\title{
PERICARDIECTOMY FOR CONSTRICTIVE PERICARDITIS
}

\author{
BY \\ C. HAVARD \\ From Sully Hospital, Glamorgan
}

(RECEIVED FOR PUBLICATION DECEMBER 15, 1956)

Pericardiectomy is well recognized as a logical and rewarding form of treatment for constrictive pericarditis. The historical background of the operation has been fully described by Sellors (1946) and it is not felt that the series of cases to be presented here has anything to add to the clinical picture of constrictive pericarditis so fully described by Evans and Jackson (1952). There are certain aspects on the surgical management of constrictive pericarditis, however, on which opinions still vary.

Which region of the heart is it particularly important to liberate when performing pericardiectomy? Is it necessary or justifiable to attempt the complete excision of the pericardium ? Is an incomplete removal of the pericardium compatible with a good functional result? What is the least traumatic exposure consistent with adequate pericardiectomy ?

These are questions which are still debated and it is the aim of this article to try to answer them.

\section{Clinical Material}

Pericardiectomy was performed on 16 patients between 1948 and 1956; the clinical course of each patient is summarized in Table $\mathrm{I}$. The average age of the patients was 34 years, the youngest being 20 years and the oldest 58 years old. Two patients, aged 51 years and 58 years, died post-operatively, the first nine days after operation due to a pulmonary embolus, the second two days after an unsatisfactory pericardiectomy in a patient with extensive pneumoconiosis and emphysema. The tuberculous aetiology was considered prove 1 in five patients, while calcification occurred in 11. Three patients were operated on while the disease appeared to be still in an active phase with no evidence of resulting spread of infection. All operations were performed through an extended left postero-lateral thoracotomy without splitting the sternum. No secondary operations have been required. An attempt was made to follow up the 14 patients who survived the operation. One patient could not be traced and another was still undergoing hospital treatment for his pulmonary tuberculosis. One other could only be traced through correspondence with her general practitioner.
The remaining 11 patients attended personally $\vec{N}$ and the length of follow-up varied from eight iv months to eight and a half years, with an average of four years. The result of the operative treatment was considered satisfactory if the patient had returned to his full occupation without symptoms even though there might be some clinical abnormality such as auricular fibrillation. On these criteria, 10 of the 11 patients who attended personally could be said to have recovered satisfactorily. The one exception, a man aged 50 years, who had been operated on only eight months previously, felt well but had not returned to work.

\section{Discussion}

Although Blalock (1951) states that adequate decortication of both sides of the heart can be performed through a long left antero-lateral thoracotomy, some form of sternal splitting procedures such as described by Holman (1949) and by Bishop and Lipin (1956) would seem necessary for complete decortication of the right auricle and venae cavae. The increased trauma and danger of the latter more extensive procedures must be balanced against the possible added benefits-the increased trauma of the more extensive exposures in often gravely ill patients and the increased danger of opening into the thin-walled auricles and veins. Occasionally adequate decortication of the heart is impossible due to the direct involvement of the myocardium in the calcification, and dissection over the auricles is hazardous in such cases. Holman (1949), in advocating median sternotomy, states that "experience indicates that it is the right side of the heart that requires the more complete decortication," and goes on to give the recorded figures of deaths of $69(26 \%)$ out of 265 patients, 21 of them on the operating table, in producing a cure in 118 $(44.5 \%)$. Satisfactory results are reported in $72 \%$ of cases by Chambliss, Jaruszewski, Brofman, Martin, and Feil (1951) and in $60 \%$ by Evans and Jackson (1952), but neither article indicates how extensive were the pericardiectomies. 
The less radical procedures have had their protagonists. A localized excision over the left ventricle was suggested by Andrews, Pickering, and Sellors (1948) as the best procedure in the grossly ill patient, a more extensive operation to follow later if required. It was suggested by Sellors (1946) that the primary, possibly the only, aim was to liberate the ventricles; while Churchill (1949), under a growing impression that the restriction was felt mainly by the ventricles, was limiting his operations accordingly.

It is not suggested that the decortication should be limited to the region of the ventricles when a more extensive excision would prove relatively easy and safe, but rather that the operation should not be considered inadequate where the ventricles only can be freed through the lateral thoracotomy. The fact that the amplitude of the ventricular beat is improved immediately on excising the pericardium locally must depend on an increased fiow through the right side of the heart and venae cavae. The improved ventricular beat is particularly obvious when the heart is further liberated by separating it from the pericardium posteriorly even though the pericardium in this region is not actually excised.

The final and best standards for measuring the success of a particular operation must be how far the patient can return to his normal occupation and how far he is rid of his pre-operative symptoms. It is felt that the results, as found on the follow-up of these patients and judged by such standards, have justified the belief in the efficacy of the more conservative measures. The following more detailed presentation of one of the series of cases (No. 10) is given to show what clinical improvement is possible following partial pericardiectomy.

\section{CASE No. 10}

This patient, a housewife aged 24 years, complained of increasing breathlessness on exertion for two years, with an enlarging abdomen and swelling of the ankles for one year. She had been confined to bed for several months. There was no history of previous serious illness and no family history of tuberculosis.

On examination, she was orthopnoeic with marked cyanosis of the lips, ears, hands, and legs. The veins of the neck and upper thorax were distended. There was a sacral pad of oedema and her legs were oedematous below the knees. The pulse was regular and there was no pulsus paradoxus. The apex beat was just palpable and the heart sounds were normal. The physical signs of bilateral pleural effusions and gross ascites were present.

Radiography of the patient's chest showed bilateral pleural effusions. Screening revealed pericardial calcification.
Paracentesis abdominis was repeated several times before her admission to Sully Hospital, up to 15 pints of ascitic fluid being removed at a time. The protein content of the ascitic fluid was as follows:

$$
\begin{array}{lllll}
\text { Total proteins } & \ldots & \ldots & \ldots & 4.0 \text { g. } \% \\
\text { Albumin } & \ldots & \ldots & \ldots & 2.4 \text { g. } \% \\
\text { Globulin } & \ldots & \ldots & \ldots & 1.6 \text { g. } \%
\end{array}
$$

On February 15, 1952, pericardiectomy was performed through a left postero-lateral thoracotomy, the sixth rib being resected. The pleura was thickened and the lower lobe of the left lung required decortication. There was a generalized thickening of the pericardium with patchy calcification. The pericardium was incised and dissected $\overrightarrow{+}$ off the anterior aspect of the right and left ventricles and along the lateral border of the left ventricle. The heart was also freed over the posterior aspect of the left ventricle and its pulsation was obviously greatly improved as a result. The left pleural cavity was drained with apical and basal tubes.

Post-operatively the patient's cyanosis and pleural effusions persisted for some weeks but finally responded to mercurial diuretics and paracenteses abdominis. She was discharged from hospital on April 5, much improved. Histological examination of the pericardium gave no clue to the aetiology.

The patient did not attend any follow-up clinic until November, 1956, four and three-quarter years after her operation. She stated that she had remained quite well since her operation with no further breathlessness, swelling of the ankles, or abdominal enlargement. She was fully able to carry out her household duties and was having no treatment of any kind.

On examination, there was no evidence of venous congestion or cyanosis. There was no clinical evidence of either ascites or oedema of the ankles. Her pulse 3 was full and regular and her cardiac impulse was easily palpable. Radiography of the chest showed extensive residual calcification mainly over the right atrium.

\section{CONCLUSIONS AND SUMmaRY}

Sixteen patients with constrictive pericarditis treated by pericardiectomy, are presented. In each 0 the pericardiectomy was limited mainly to the region $\tilde{\omega}$ of the ventricles. It was the aim of the study to decide whether this more conservative procedure was consistent with a good functional result. It was $\stackrel{\oplus}{\circledR}$ felt that the follow-up findings proved this to be so. An extended postero-lateral thoracotomy proved 0 an adequate exposure for this operation. One case $\mathbb{\mathbb { D }}$ is presented in detail to show what clinical improve- $\mathbb{D}$ ment is possible following liberation of the ventricles $\overline{2}$ only, even though the right side of the heart remains encased in calcification. 
All the patients included in this series were operated on by Mr. Dillwyn M. E. Thomas, and I am indebted to him for his help and encouragement in this study. My thanks are due also to Dr. H. M. Foreman, M.B.E., Dr. L. R. West, and Dr. D. A. Williams, under whose care the patients were admitted, for making the case notes available. Finally I wish to thank Miss P. Densley for the typing.

\section{REFERENCES}

Andrews, G. W. S., Pickering, G. W., and Sellors, T. H. (1948). Quart. J. Med., 17, 291

Bishop, C. A., and Lipin, R. J. (1956). J. thorac. Surg., 31, 686.

Blalock, A. (1951). Ibid., 21, 543.

Chambliss, J. R., Jaruszewski, E. J., Brofman, B. L., Martin, J. F., and Feil, H. (1951). Circulation, 4, 816.

Churchill, E. D. (1949). J. thorac. Surg., 18, 650.

Evans, W., and Jackson, F. (1952). Brit. Heart J., 14, 53.

Holman, E. (1949). J. thorac. Surg., 18, 643.

Sellors, T. H. (1946). Brit. J. Surg., 33, 215. 